\title{
Lipid peroxidation in multidrug-resistant Gram-negative sepsis: translating science to the septic patient?
}

\author{
Patrick Scheiermann 1,2,* and Soeren E Pischke ${ }^{3}$ \\ See related research by Toufekoula et al., http://ccforum.com/content/17/1/R6
}

\begin{abstract}
Multidrug-resistant Gram-negative induced sepsis poses an increasing threat to the vulnerable intensive care patient. The study by Toufekoula and colleagues reports the serum and tissue concentration of malondialdehyde (MDA), the toxic end product of lipid peroxidation, during the course of experimental and human Gram-negative sepsis. The complementary results from this dual experimental and clinical approach argue for highly compartmentalized lipid peroxidation during sepsis. Establishing a correlation between MDA concentration and survival provides valuable insights into the pathophysiology of Gramnegative sepsis. Yet, further studies are needed to understand and establish MDA as a biomarker during sepsis aggravated by organ failure.
\end{abstract}

In the previous issue of Critical Care, Toufekoula and colleagues [1] investigated the serum and tissue concentrations of malondialdehyde (MDA) as readout for lipid peroxidation during sepsis. They submitted rats to sepsis by multidrug-resistant (MDR) isolates of Pseudomonas aeruginosa, which showed significantly higher MDA concentrations in liver, spleen and aorta compared to control animals. The rat data were compared to an historic cohort of patients $(\mathrm{n}=93)$ with MDR Gramnegative bacteria-induced ventilator-associated pneumonia, in which MDA serum concentrations during the first 7 days were elevated and correlated with survival during sepsis-induced hepatic or cardiopulmonary failure.

*Correspondence: pscheiermann@googlemail.com

'Department of Anesthesiology, Hospital of the Ludwigs-Maximilians-University,

Marchioninistr. 15, 81377 Munich, Germany

Full list of author information is available at the end of the article
Sepsis induced by MDR Gram-negative bacteria is a growing concern in intensive care units [2]. A vulnerable patient population, long-term use of invasive medical equipment and increasing use of broad-spectrum antibiotics considerably affect overall morbidity, mortality and health care costs [3]. Despite the amount of research in the field of sepsis, a link between specific toxic mediators and patient outcome, which would enable biomarkers of organ failure to be defined and therapy adjusted accordingly, has not been established.

The study by Toufekoula and colleagues [1] features a dual approach to the organ distribution pattern of lipid peroxidation during sepsis. In vivo data from rats were compared to patient data from a historic study cohort [4]. This combined approach greatly enhances the value of the study since transferring results from rodent models to the clinical situation in septic patients is challenging [5]. Thus, comparing experimental and clinical data as presented by Toufekoula and colleagues is an excellent example of translational research.

In the rat sepsis model, one MDR P. aeruginosa isolate from one patient was investigated. However, in ventilatorassociated pneumonia different strains of $P$. aeruginosa may differ considerably with regard to onset and mortality [6,7]. Moreover, the pattern in which organs are affected differs according to the infectious agent [8]. Thus, the patterns of MDA production as reported by Toufekoula and colleagues might not be extrapolated to sepsis induced by other types of bacteria, which emphasizes the need to stratify both rodent and human sepsis for the underlying pathogen. Additionally, Toufekoula and colleagues induced sepsis in the rats by intraperitoneal injection, while sepsis in patients was caused by bacterial migration through the lung. This might explain why patients with pulmonary failure (that is, acute respiratory distress syndrome) showed high circulating MDA levels whereas pulmonary MDA concentrations in septic rats remained rather unchanged. This highlights the fact that the way organs are affected in 
humans might differ markedly from animal models [9] and may be directly dependent on the route of infection.

MDA is a biomarker for lipid peroxidation indicating oxidative stress [10]. Recently, circulating lipid peroxidation products (other than MDA) during sepsis were shown to correlate with increased hospital mortality rates [11]. However, the present study shows that the concentrations of circulating MDA have to be interpreted with utmost caution in septic patients. Survivors among septic patients with hepatic dysfunction or with acute respiratory distress syndrome and concomitant cardiovascular failure showed higher circulating MDA concentrations than non-survivors. In contrast, survivors with acute renal dysfunction displayed lower circulating MDA levels than non-survivors. Questions concerning the underlying mechanism or the hypothesis that a toxic end product may predict survival under certain circumstances cannot be answered from this descriptive study. Microdialysis is an established method to monitor both metabolic and inflammatory markers in clinical settings [12]. Several methods for MDA detection in microdialysis fluid have been described [13] and it would be of great interest to evaluate MDA production directly in different organs throughout the course of sepsis. Nevertheless, as an additional parameter, circulating MDA may potentially become a valuable tool in evaluating septic patients concordant with the recently proposed model of 'bioscore' combining different biomarkers in one model [14].

\section{Conclusions}

Understanding the pathophysiology during MDR P. aeruginosa-induced ventilator-associated pneumonia and sepsis is desperately needed as infection rates are likely to increase in the future and novel therapeutic options will not be readily at hand [15]. The study by Toufekoula and colleagues provides valuable information about MDR $P$. aeruginosa-induced sepsis and, thus, a data foundation for MDA quantification in vital organs. Although the data are entirely descriptive, the study sheds light on MDA as a promising biomarker, which may potentially facilitate the evaluation of intensive care patients during the course of severe sepsis.

Abbreviations

MDA, malondialdehyde; MDR, multidrug-resistance.

Competing interests

The authors declare that they have no competing interests.

\section{Author details}

'Department of Anesthesiology, Hospital of the Ludwigs-MaximiliansUniversity, Marchioninistr. 15, 81377 Munich, Germany. ${ }^{2}$ pharmazentrum frankfurt/ZAFES, Hospital of the Goethe-University, Theodor-Stern-Kai 7 , 60590 Frankfurt am Main, Germany. ${ }^{3}$ Division of Emergencies and Critical Care, Department of Anaesthesiology, Oslo University Hospital, PO Box 4950, 0424 Oslo, Norway.
Published: 1 March 2013

\section{References}

1. Toufekoula C, Papadakis V, Tsaganos T, Routsi C, Orfanos SE, Kotanidou A, Carrer DP, Raftogiannis M, Baziaka F, Giamarellos-Bourboulis EJ: Compartmentalization of lipid peroxidation in sepsis by multidrugresistant gram-negative bacteria: experimental and clinical evidence. Crit Care 2013, 17:R6.

2. Sievert DM, Ricks P, Edwards JR, Schneider A, Patel J, Srinivasan A, Kallen A Limbago B, Fridkin S: Antimicrobial-resistant pathogens associated with healthcare-associated infections: summary of data reported to the National Healthcare Safety Network at the Centers for Disease Control and Prevention, 2009-2010. Infect Control Hosp Epidemiol 2013, 34:1-14.

3. Brusselaers $N$, Vogelaers $D$, Blot $\mathrm{S}$ : The rising problem of antimicrobial resistance in the intensive care unit. Ann Intensive Care 2011, 1:47.

4. Giamarellos-Bourboulis EJ, Pechere JC, Routsi C, Plachouras D, Kollias S, Raftogiannis M, Zervakis D, Baziaka F, Koronaios A, Antonopoulou A, Markaki V, Koutoukas P, Papadomichelakis E, Tsaganos T, Armaganidis A, Koussoulas V, Kotanidou A, Roussos C, Giamarellou H: Effect of clarithromycin in patients with sepsis and ventilator-associated pneumonia. Clin Infect Dis 2008, 46:1157-1164.

5. Deitch EA: Rodent models of intra-abdominal infection. Shock 2005, 24(Suppl 1):19-23.

6. Bassetti M, Taramasso L, Giacobbe DR, Pelosi P: Management of ventilatorassociated pneumonia: epidemiology, diagnosis and antimicrobial therapy. Expert Rev Anti Infect Ther 2012, 10:585-596.

7. Pena C, Gomez-Zorrilla S, Oriol I, Tubau F, Dominguez MA, Pujol M, Ariza J: Impact of multidrug resistance on Pseudomonas aeruginosa ventilatorassociated pneumonia outcome: predictors of early and crude mortality. Eur J Clin Microbiol Infect Dis 2013, 32:413-420.

8. Chinnaiyan AM, Huber-Lang M, Kumar-Sinha C, Barrette TR, Shankar-Sinha S, Sarma VJ, Padgaonkar VA, Ward PA: Molecular signatures of sepsis: multiorgan gene expression profiles of systemic inflammation. Am J Pathol 2001, 159:1199-1209.

9. Rittirsch D, Hoesel LM, Ward PA: The disconnect between animal models of sepsis and human sepsis. J Leukoc Bio/ 2007, 81:137-143.

10. Horton JW: Free radicals and lipid peroxidation mediated injury in burn trauma: the role of antioxidant therapy. Toxicology 2003, 189:75-88.

11. Ware LB, Fessel JP, May AK, Roberts II LJ: Plasma biomarkers of oxidant stress and development of organ failure in severe sepsis. Shock 2011, 36:12-17.

12. Haugaa H, Almaas R, Thorgersen EB, Foss A, Line PD, Sanengen T, Bergmann GB, Ohlin P, Waelgaard L, Grindheim G, Pischke SE, Mollnes TE, Tonnessen TI: Clinical experience with microdialysis catheters in pediatric liver transplants. Liver Transpl, in press.

13. Cooley JC, Lunte CE: Detection of malondialdehyde in vivo using microdialysis sampling with CE-fluorescence. Electrophoresis 2011, 32:2994-2999.

14. Gibot S, Bene MC, Noel R, Massin F, Guy J, Cravoisy A, Barraud D, De Carvalho Bittencourt M, Quenot JP, Bollaert PE, Faure G, Charles PE: Combination biomarkers to diagnose sepsis in the critically ill patient. Am J Respir Crit Care Med 2012, 186:65-71.

15. Boucher HW, Talbot GH, Bradley JS, Edwards JE, Gilbert D, Rice LB, Scheld M, Spellberg B, Bartlett J: Bad bugs, no drugs: no ESKAPE! An update from the Infectious Diseases Society of America. Clin Infect Dis 2009, 48:1-12.

\section{doi:10.1186/cc12505}

Cite this article as: Scheiermann P, Pischke SE: Lipid peroxidation in multidrug-resistant Gram-negative sepsis: translating science to the septic patient? Critical Care 2013, 17:120. 